\title{
Evaluation of gastrointestinal helminths in canine population of Bhubaneswar, Odisha, India: a public health appraisal
}

\author{
P. N. Panigrahi ${ }^{1,2}$, A. R. Gupta ${ }^{2}$, Sujit K. Behera ${ }^{3}$, B. S. K. Panda ${ }^{2}$, R. C. Patra ${ }^{2}$, B. N. Mohanty ${ }^{2}$ and G. R. Sahoo $^{2}$ \\ 1. Division of Veterinary Medicine, Indian Veterinary Research Institute, Izatnagar -243122, Uttar Pradesh, India; \\ 2. College of Veterinary Science and Animal Husbandry, Orissa University of Agriculture and Technology, \\ Bhubaneswar -751 003, Odisha, India; 3. Division of Veterinary Public Health, Indian Veterinary Research Institute, \\ Izatnagar -243122, Uttar Pradesh, India \\ Corresponding author: P. N. Panigrahi, email: pnpvetmed@gmail.com \\ Received: 03-03-2014, Revised: 04-04-2014, Accepted: 08-04-2014, Published online: 07-05-2014
}

doi: 10.14202/vetworld.2014.295-298 How to cite this article: Panigrahi PN, Gupta AR, Behera SK, Panda BSK, Patra RC, Mohanty BN and Sahoo GR (2014) Evaluation of gastrointestinal helminths in canine population of Bhubaneswar, Odisha, India: a public health appraisal, Veterinary World 7(5): 295-298.

\begin{abstract}
Aim: To evaluate the presence of gastrointestinal helminthic parasites in clinically apparent canines of Bhubaneswar, Odisha and to determine the risk of zoonotic infection to dog owners through questionnaire survey.

Materials and Methods: A total of $154 \mathrm{dogs}$, with clinical signs of gastroenteritis were examined for the presence of helminthic ova and /or larvae in their faecal sample by direct smear and/ or floatation and centrifugation method. Prevalence was determined by sex wise, age wise, and breed wise. A structured questionnaire on 50 dog owners was designed to gather information on dog ownership, management and related risks on public health.

Results: In the present investigation, the overall prevalence of gastrointestinal helminths infection was $41.46 \%$. The infection rate was highest for mixed parasitic infection (26.57\%) followed by Ancylostoma caninum (23.44\%), Toxocara canis $(20.31 \%)$ and lowest for Taenia spp. (3.13\%). In relation to different groups, the prevalence was higher in male than female, highest in younger animals and it was shown a decreasing trend as age increased. It was also higher in non-descriptive breeds than pure and exotic breeds. Very few dog owners $(10 \%)$ were conscious about that canine parasite could be transmitted to humans but none of them could provide correct information on the mode of transmission. Only $12 \%$ dog owners had maintained standard deworming schedule.
\end{abstract}

Conclusion: The findings showed that the high levels of ignorance among dog owners about canine helminthic parasites and transmission coupled with significant infection rates among the dogs in the community warrants immediate action needs to be taken to decrease infection rate in dogs and to raise awareness among the community about zoonotic diseases.

Keywords: dog, helminths, prevalence, zoonosis.

\section{Introduction}

Parasitic diseases account for important health hazard in human beings and animals around the globe including India [1]. India, as a tropical country, has a wide range of climatic zones, which make it vulnerable for a diverse range of parasites of medical and veterinary importance, whose transmission and geographical distribution are closely linked to regional temperature, rainfall and humidity.

Gastrointestinal helminthiasis is the most commonly encountered disease in dogs and also acts as a major constraint in dog rearing across the globe including India [2]. The distribution and intensity of the diseases are mainly influenced by geographical, climatic, cultural and economic factors [3]. Furthermore, the level of hygienic conditions, lack of veterinary supervision and less awareness concerning zoonotic diseases exacerbate the transmission of these diseases. Epidemiological pattern of the parasitic diseases in the different agro-climatic zones of the country usually provides a basis for developing strategic and tactical

Copyright: The authors. This article is an open access article licensed under the terms of the Creative Commons Attribution License (http://creativecommons.org/licenses/by/2.0) which permits unrestricted use, distribution and reproduction in any medium, provided the work is properly cited. control systems against them [2-3]. Several studies on epidemiology of canine intestinal parasites have been reported in many parts of the world including India [49]. In India, perusal of literature revealed prevalence of helminths infection were $2.21 \%$ in Pudduchery [4], $19.71 \%$ in Punjab [5], $19.5 \%$ in Jabalpur [6], 24.3\% in Bareilly, Uttar Pradesh [7] and 40.4\% in Bangalore[8].

Canine parasitic zoonosis poses a continuing public health problem, especially in a developing country like India. Zoonotic parasites can cause significant morbidity in all groups of the human population, with particular reference to vulnerable groups, such as children, the elderly, and the immunocompromised individuals and lists include Toxocara canis, Ancylostoma caninum, Echinococcus granulosus etc. [9-12]. Migrating larvae of T. canis can cause visceral larva migrants (VLM), ocular larva migrants (OLM) in humans [10]. A. caninum and A. braziliense had also been reported in cutaneous larva migrants (CLV) and eosinophilic enteritis in human [13]. Several studies of canine intestinal parasites along with their public health threats have been reported in many parts of the world including India [9-17].

However, such a report is absent in Odisha, India. Therefore, the Hospital based survey in Bhubaneswar; 
Table-1: Knowledge and attitudes of dog owners regarding potential zoonotic helminthic disease in Bhubaneswar, Odisha, India.

\begin{tabular}{|c|c|c|}
\hline Variables & No. & $\%$ \\
\hline \multicolumn{3}{|l|}{ Dog ownership* } \\
\hline Pet & 27 & 54 \\
\hline Family dog & 16 & 32 \\
\hline Community dog & 7 & 14 \\
\hline Feral dog & - & - \\
\hline \multicolumn{3}{|l|}{ Occupation of owner } \\
\hline Farmer & 14 & 28 \\
\hline Government employee & 12 & 24 \\
\hline private employee & 24 & 48 \\
\hline \multicolumn{3}{|l|}{ Reason for keeping dog } \\
\hline Look after house & 14 & 28 \\
\hline Look after livestock & 11 & 22 \\
\hline Show & 17 & 34 \\
\hline Hunting & 2 & 4 \\
\hline No specific reason & 6 & 12 \\
\hline \multicolumn{3}{|l|}{ Housing of dogs } \\
\hline Confined to dog house on compound & 5 & 10 \\
\hline Share the same house with owner & 45 & 90 \\
\hline \multicolumn{3}{|l|}{ Feeding of dog } \\
\hline Household food & 11 & 22 \\
\hline Commercial dog food & 5 & 10 \\
\hline Condemned offal and human leftover food & 34 & 68 \\
\hline \multicolumn{3}{|l|}{ Usual place of defecation of dogs } \\
\hline Within the house premises and grazing area & 50 & 100 \\
\hline \multicolumn{3}{|c|}{ Dog owners' perception of diseases transmitted by dogs } \\
\hline Serious & 5 & 10 \\
\hline Not serious & 22 & 44 \\
\hline Do not cause any diseases & 23 & 46 \\
\hline \multicolumn{3}{|l|}{ Do children play with dogs } \\
\hline Yes & 50 & 100 \\
\hline No & - & - \\
\hline \multicolumn{3}{|l|}{ Deworming } \\
\hline Maintain schedule & 6 & 12 \\
\hline Do not maintain schedule & 44 & 88 \\
\hline
\end{tabular}

*dogs were grouped in to four categories according to Menezes, 2008 [27]

Odisha was carried out to determine the prevalence of gastrointestinal helminthic diseases in canines and risk of zoonotic infection to dog owners.

\section{Materials and Methods}

Ethical approval: The approval for collecting faecal samples and examination of dogs was taken from Institutional Animal Ethics Committee.

Study area: Odisha, on the eastern sea board of India, enjoys a tropical monsoon type climate like most other parts of the country. The present study was undertaken in the Department of Medicine and Teaching Veterinary Clinical Complex, College of Veterinary Science and Animal Husbandry, Orissa University of Agriculture and Technology, Bhubaneswar from December 2012 to June, 2013. Bhubaneswar, the capital city of Odisha was chosen for study area, as here amalgamation of dog breeds are available starting from mongrels to pure and cross breed with sizeable number of population used as pets.

Animals: Dogs $(n=154)$, of any breed, either male or female, of any age groups, presented to Teaching Veterinary Clinical Complex, Bhubaneswar with clinical signs of gastroenteritis such as vomition, diarrhoea, tympanitis, flatulence were examined to rule out parasitic infection as a routine diagnostic procedure. The presence of parasitic ova in their faecal sample through direct smear and/or floatation technique was evaluated. Some dog population have been suspected for mixed infection like parvo viral gastroenteritis, infectious canine hepatitis or leptospirosis without any report of malignancy.

Collection of samples: Faecal samples were collected from the dogs in pre- labelled specimen bottles at morning hours and examined immediately.

Examination of faeces: The collected faecal samples of dogs were examined for presence of helminths ova and/or larvae by direct smear method and/ or floatation method by using saturated $\mathrm{NaCl}$ solution of specific gravity 1.18-1.19. Identification of the parasitic ova was made according to the morphological characteristics and keys as described earlier [18].

Questionnaire survey: A structured questionnaire consisting of 50 questions was prepared in local language and a pilot test to assay the questionnaire was performed. The questionnaire was designed to gather information on dog ownership, feeding of dogs, treatment for dogs, the extent of awareness on dog parasites, control measures taken, the occupation of the dog's owner and other related factors. The participants were selected based on simple random sampling.

Statistical analysis: The data were analysed statistically by SPSS software [19] to determine prevalence.

\section{Results}

Questionnaire survey: Table-1 shows the detailed questionnaire survey. In most of the cases, dogs were 
Table-2: Distribution of different types of parasites.

\begin{tabular}{lcc}
\hline Species of parasite & No. of dogs infected & Percentage (\%) \\
\hline Toxocara canis & 13 & 20.31 \\
Ancylostoma caninum & 15 & 23.44 \\
Dipylidium caninum & 8 & 12.50 \\
Taenia spp. & 2 & 03.13 \\
Trichuris vulpis & 6 & 09.37 \\
Toxocara leonina & 3 & 04.68 \\
Mixed infection & 17 & 26.57 \\
Total & 64 & 100.00 \\
\hline
\end{tabular}

Table-3: Prevalence of gastrointestinal helminths in dogs in relation to age.

\begin{tabular}{lcccc}
\hline Sr. No. & Age group & Total no. of dogs examined & Dogs found positive & Prevalence percentage \\
\hline 1 & $3-6$ month & 47 & 25 & 19 \\
2 & $6-12$ month & 41 & 14 & $46.34 \%$ \\
3 & $1-2$ year & 39 & 5 & $35.90 \%$ \\
4 & $2-5$ year & 19 & 1 & $26.32 \%$ \\
5 & $>5$ year & 8 & $12.50 \%$ & 64 \\
\hline
\end{tabular}

maintained unhygienically, defecating within the house premises and grazing area (100\%) and sharing common house with owners $(90 \%)$. Very few owners $(10 \%)$ knew that canine parasites could be transmitted to humans. Of the owners who were aware of the potential for transmission of parasites from dogs to humans, none of them could provide correct information on the mode of transmission. Only $12 \%$ of the dog owners had maintained standard deworming schedule in their lifetime.

Prevalence: Out of 154 dogs, 64 dogs were found positive for one or more ova and/or larvae of gastrointestinal (GI) helminths. Hence, the overall prevalence of gastrointestinal helminths was $41.56 \%$. The distribution of different types of parasites and their prevalence was shown in Table-2. The infection rate was highest for mixed parasitic infection (26.57\%) followed by $A$. caninum $(23.44 \%)$, T. canis $(20.31 \%)$ and lowest for Taeniea spp. (3.13\%).Of the 154 dogs (58 Male, 96 Female) examined, 26 male and 38 female dogs were found positive for gastrointestinal helminthic infections having prevalence of $44.83 \%$ and $39.58 \%$, respectively.

Distribution of animals in five different groups based on age (3-6 month, 6-12 month, 1-2 year, 2-5 year and more than 5 years of age) revealed highest percentage of prevalence in 3-6 month age group i.e. $53.19 \%$. There were decreasing trends of percentage of prevalence of gastrointestinal helminthic infections, as age of dog increasing. The percent prevalence of parasitism in different age groups is depicted in (Table-3).

A total 34 of the 89 pedigree dogs $(38.20 \%), 14$ out of 34 mixed breed dogs $(41.18 \%), 13$ of 31 nondescriptive stray dogs (41.93\%) were reported positive. Percent prevalence of GI helminthic infection was highest in non-descriptive dogs (mongrels) and lowest in pedigree breeds.

\section{Discussion}

Gastrointestinal helminthiasis is the most commonly encountered disease in dogs rearing across the globe including India [2]. India, as a tropical country, has a wide range of climatic zones, from montane (cold, wet alpine) and semi-arid regions to the wet tropics, which make it suitable for a diverse range of parasites and pathogens of medical and veterinary importance. Their transmission and distribution are mostly influenced by geographical, climatic, cultural and socio-economic factors.

The role of dogs as companion animals and the close relationship between humans and dogs, although offering significant benefits to many people, also represent a potential public health risk, as natural transmission of parasitic infections from dogs to humans may occur directly or indirectly via environmental factors. All kinds of dogs (owned and stray dogs) are involved in transmission, even if the particular implication of each population is not clearly established [10].

In the present investigation, the overall prevalence of gastrointestinal helminths in dogs was $41.56 \%$. Similar findings were also obtained in various surveys in different countries across the world including India which varies from $2.21 \%-40.56 \%$ [4-9, 14-16]. Minor variation in the results in these surveys is attributable due to geographical variation, environmental factors, sample size, clinically apparent symptomatic dog population and other stress factors involved in parasite transmission.

The prevalence of GI helminths was highest in 3-6 months age groups $(53.19 \%)$ of dogs and the prevalence decreases as age increases and became lowest in more than 5-year age group $(12.50 \%)$. These results are in agreement with earlier findings [7, 10, 12, 17, 20-21]. Higher prevalence rate in younger dogs might be due to the transplacental and transmammary passage of larvae to the puppies $[17,22]$. This difference might also be due to the low level of immunity of young pups to plethora of infections including parasitic infection [24, 25]. The prevalence of infection with respect to breed revealed higher percentage in nondescriptive local dogs $(41.93 \%)$ than mixed breed and exotic breed of dogs, that may either be due to poor management or unhygienic habits of non-descriptive 
local dogs in contrast to routine anthelmintic treatment given to pure breeds and their usage as pet purpose with little access to outside environment. Similar findings were also reported by various researchers in several studies $[7,23,26]$.

\section{Conclusion}

The study showed the presences of different helminths in a single host as well as high frequency of these parasites in the study area warrants immediate attention to assess the pathogenic impact of the parasites in terms of growth, prolificacy of animals. In addition, parasites of zoonotic importance were highly prevalent in dogs, so intervention measures are necessary to reduce the risk of transmission of parasites from dogs to humans. Interventions, those are need of this hour should focus on health education provided to dog owners, strategic deworming of dogs using broad spectrum anthelmintic and proper sanitation and hygiene.

\section{Authors' contributions}

ARG and RCP planned and designed the whole study. PNP collected sample, carried out the whole work and write the manuscript. BNM helped in identification of parasites and microscopic examination. SKB, BSKP and GRS helped during manuscript writing, cross checking and revision. All authors read and approved the final manuscript.

\section{Acknowledgments}

The authors are highly thankful to Dean, College of Veterinary Science and Animal Husbandry and Director, Teaching Veterinary Clinical Complex for their cooperation and provision of research facilities. The fund for the study was provided by Department of Veterinary Medicine, College of Veterinary Science and Animal Husbandry, Bhubaneswar.

\section{Competing interests}

The authors declare that they have no competing interests.

\section{References}

1. Panigrahi, P.N., Gupta, A.R., Patra, R.C., Mohanty, B.N., Maiti, A. and Sahoo, G.R. (2014) Comparative anthelmintic efficacy of ivermectin delivered through different routes in gastrointestinal nematode infected dogs. J. Parasit. Dis., DOI 10.1007/s12639-014-0441-7.

2. Traub, R.J., Hobbs, R.P., Adams, P.J., Behnke, J.M., Harris, P.D. and Thompson, R.C. (2007) A case of mistaken identity reappraisal of the species of canid and felid hookworms (Ancylostoma) present in Australia and India. Parasitology. 134:113-119.

3. Robertson, I. D., Irwin, P. J., Lymbry, A. J. and Thompson, R. C.A. (2000) The role of companion animals in the emergence of parasitic zoonosis. Int J Parasitol. 30: 1369-1377.

4. Das, S.S., Kumar, D., Sreekrishnan, R. and Ganesan, R (2009) Soil contamination of public places, play grounds and residential areas with ova of Toxocara. Indian. J. Vet. Res, 17(2):13-16.

5. Harbinder, S., Bali, H.S. and Kaur, A. (1997). Prevalence of Toxocara spp. eggs in the soil of public and private places in Ludhiana and Kellon area of Punjab, India. Epidemiol. Santé Anim., 31-32.

6. Qadir, S., Dixit, A. K., Dixit, P and Sharma, R. L (2011)
Intestinal helminths induce haematological changes in dogs from Jabalpur, India. J. Helminthol 85 (4): 401-403.

7. Sahu, S., Samanta, S., Sudhakar, N.R., Raina, O.K., Gupta, S.C., Maurya, P.S., Pawade, A.M. and Kumar, A. (2014). Prevalence of canine toxocariasis in Bareilly, Uttar Pradesh, India. J. Parasit. Dis., 38 (1): 111-115.

8. D`souza, P. E., Dhanalakshmi, H. and Jaganath M. S. (2002) Soil contamination with canine hookworm and round worm ova in Bangalore. J. Parasit. Dis., 26:107-108.

9. Ahmad, N., Maqbool, A., Saeed, K., Ashraf, K and Qama, M. F. (2011) Toxocariasis, its zoonotic importance and chemotherapy in dogs. J. Anim. Plant Sci. 21(2): 142-145.

10. Dogan, N., Dinleyici, E.C., Bor, O., Toz, S.O. and Ozbel, Y. (2007) Seroepidemiological survey for Toxocara canis infection in the northwestern part of Turkey. Turkiye Parazitol Derg. 31:288-291.

11. Traub, R. J., Robertson, I. D., Irwin, P., Mencke, N., Monis, P. and Thompson, A.C.R. (2003) Humans, Dogs and parasitic zoonosis- unravelling the relationship in a remote endemic community in North East India using molecular tools. Parasitol Research.90(3): 156-157.

12. Carmena, D. And Cardona, G.A. (2013).Canine echinococcosis: Global epidemiology and genotype diversity. Acta Trop., 128(3): 441-460.

13. Prociv, P. and Croese, J. (1996) Human enteric infection with Ancylostoma caninum: hookworms reappraised in the light of a "new" zoonosis. Acta Trop. 62:23-44.

14. Basu, J., Islam, M.M., Rahman, M.W., Alam, M.R. and Parvez, M.M. (2010) Study on identification and prevalence of common gastrointestinal parasitic infection in domestic dog in Chittagong district. Int. J. Anim Fisher. Sci., 3: 354-356.

15. Egura-Aguilar, P., Cruz-Reyes, A. and Martrnez-Maya, J. J. (2005) Ecological analysis and description of the intestinal helminths present in dogs in Mexico City. Vet. Parasitol. 127:139-146.

16. Umar, Y.A. (2009) Intestinal helminthoses in dogs in Kaduna Metropolis, Kaduna State, Nigeria. Iranian J Parasitol. 4: 34-39.

17. Ambily V.R., Pillai, U.N., Arun, R., Pramod, S. and Jayakumar, K.M. (2011). Detection of human filarial parasite Brugia malayi in dogs by histochemical staining and molecular technique. Vet Parasitol. 181:210-214.

18. Soulsby, E. J. L. (1982) Helminths Arthropods and Protozoa of Domestic Animals. 7th Ed Baillire Tindall and Cassell Ltd, London. p92-354.

19. Snedecor, G.W. and Cochran, W.G. (1967) Statistical Methods, 6th ed. Oxford and IBH, New Delhi. p258-268.

20. Andresiuki, V., Sardellai, N. and Denegri, G. (2007) Seasonal fluctuations in prevalence of dog intestinal parasites in public squares of Mar del Plata city, Argentina and its risk for humans. Rev Argent Microbiol. 39: 221-224.

21. Endrias, Z., Semahegn, Y. and Mekibib, B. (2010) Prevalence of helminth parasites of dogs and owners awareness about zoonotic parasites in Ambo town, central Ethiopia. Ethiop. Vet J. 14: 17-30.

22. Bowman, D.D. (2009) Georgi's Parasitology for Veterinarians. 9th edition.: Saunders Company. p182-183.

23. Kutdang, E.T., Bukbuk, D. N. and Ajayi, J. A. A. (2010) The Prevalence of Intestinal Helminths of Dogs (Canis familaris) in Jos, Plateau State, Nigeria. Researcher. 2 (8): 51-56.

24. Borecka, A. (2005) Prevalence of intestinal nematodes of dogs in Wassaw area, Poland. Helmithologica 42: 35-39.

25. Das, Shubhagata, Alim, Md. Abdul, Sikder, Suchandan, Das Gupta, Aungshuman, Masuduzzaman, Md. (2012) Prevalence and Worm Load Of Enteric Helminthiasis In Stray Dogs Of Chittagong Metropolitan, Bangladesh. YYU Veteriner Fakultesi Dergisi. 23 (3): 141-145.

26. Chattha, M. A., Aslam, A., Rehman, Z. U., Khan, J. A. and Avais, M. (2009) Prevalence of toxocara canis infection in dogs and its effects on various blood parameters in Lahore (Pakistan). J. Anim. Plant Sci. 19(2): 71-73.

27. Menezes, R. (2008) Rabies in India. Can Med Assoc J. 178:564.

$* * * * * * * *$ 